\title{
artículos
}

\section{La Hacienda de Giró: Un patrimonio emblemático malagueño irrecuperable}

Julia de la Torre Fazio

Universidad de Málaga

PALABRAS CLAVE: Arquitectura s. XIX/ Patrimonio/ Málaga

\section{RESUMEN}

La Hacienda de Giró, hoy desaparecida, fue una de las grandes villas malagueñas del siglo XIX

Su propietario, Juan Giró, creó un jardín y un conjunto artístico muy notables que se convertirían en referencia de la burguesía malagueña. A su muerte, la finca fue vendida y utilizada como hotel, uso que tendría hasta mitad del pasado siglo XX, momento en el que fue convertida en colegio y residencia de estudiantes. Durante algunos años se conservaron tanto la casa como el jardín pero en la década de los setenta la casa fue derribada y el jardín convertido en instalaciones deportivas.

ABSTRACT

The "Hacienda de Giro", nowadays vanished, was one of the greatest villas in 19th century Malaga. Its owner, Juan Giró, created very remarkable artistic setting along with a garden, which became a meeting point for Malaga's raising middle class. Upon his death, the villa was sold and became a hotel until mid 20th century, when it finally became the school it now is. For some years, both the garden and the main house were preserved, however, in the 70 's the house was demolished and the gardens were turned into sporting facilities.

Empecemos por el final. En un gran solar del Monte de Sancha tiene su sede en Málaga, desde hace ya más de cuarenta años, la Institución Teresiana. La Academia de Santa Teresa es un edificio moderno de módulos escalonados con terrazas-jardín realizado en 1963 por Manuel Barbero Rebolledo y Rafael de la Joya Castro ${ }^{1}$. A escasos metros del colegio se encuentra el Centro Almar, residencia de teresianas, construido posteriormente tras el derribo de una casa de dos pisos del siglo XIX. Hoy tan sólo unas semiocultas barandillas de hierro forjado permiten intuir un pasado diferente.

*DE LA TORRE FAZIO, Julia: "La Hacienda de Giró. Un patrimonio emblemático malagueño irrecuperable", Boletín de Arte, $\mathrm{n}^{\circ}$ 28, Departamento de Historia del Arte, Universidad de Málaga, 2007, págs. 191-206. 


2: artículos Julia de la Torre Fazio

UN POCO DE HISTORIA.

Y ahora retrocedamos hasta el principio, al siglo XV. La primera noticia que tenemos de estas tierras se las debemos a Fray Alonso de Rivera, ermitaño, que en Sevilla a 23 de mayo de 1499 donó al Real Convento de la Merced de Málaga el almendral y tierras donde antiguamente había habido una ermita y una casa de la Santa Vera Cruz. Desde esa fecha disponemos de algunos datos sueltos que nos indican los cambios de propietarios.

En 1585 el Convento otorga el terreno, a censo perpetuo, a Francisco de Sandoval e Isabel Pérez. En 1661 Catalina Jiménez, viuda de Juan Sánchez de Revaneda, compra la finca a Francisco Portillo. El 31 de diciembre de 1773 los herederos de Francisco de Torres la venden a Francisco Rodríguez de Castro, y éste, en 1790, a Juan Morales, que en 1791 vende una parte a Manuel Muriel. A su vez, pasados unos años, en 1811, Manuel Muriel y Francisca Caballero venden a Domingo Sicardo. En marzo de 1825 los herederos de Sicardo venderán a Antonio Sánchez, padre de María Dolores Sánchez Morales².

Paralelamente, y para entender el desarrollo de los acontecimientos, en un terreno colindante a estas tierras, en la Hacienda La Bonita ${ }^{3}$, comprada a Francisco Sánchez en 1841 se establece la Sociedad y Empresa de Herrería "El Ángel"4.

"El Ángel" se había fundado en 1831 con la participación de numerosos socios - Tomás Gazzino, Juan Bautista Bisso, Joaquín García, José Garci, Juan Manescau, José Pedro Hue y Miguel Moreno Avilés, entre otros- tras la disolución de la Sociedad Anónima de la Herrería de "Nuestra Señora de la Concepción" en 1826. Después de establecerse en Marbella, junto al Río Verde, y montar un martinete y altos hornos, "El Ángel", siguiendo una vez más los pasos de Heredia, decide establecerse en Málaga, para lo cual compra la Hacienda la Bonita 5 .

Inmediatamente después de la compra, Juan Giró, que no era socio fundador pero que poco después adquiriría acciones y se convertiría en director de la herrería, solicita atirantado para construir una fábrica de fundición en la Malagueta (Hacienda la Bonita) ${ }^{6}$. Del buen hacer de Giró como director tenemos noticia gracias a la Guía

1 CAMACHO MARTínEZ, Rosario (dir.), Guía histórico-artística de Málaga, Arguval, Málaga, 1997.

2 Archivo privado Kusche. Vid. a. HURTADO SUÁREZ, Inmaculada, "La Folie Giro: Vista Hermosa, una de las primeras residencias de recreo de la burguesía malagueña" (artículo inédito).

3 En la actualidad ese espacio está ocupado por los pisos de Cantó.

4 (A)rchivo (H)istórico (P)rovincial de (M)álaga, leg. 4128, fol. 974.

5 "Fábrica de Fundición EI Ángel" en HEREDIA GARCÍA, Guillermo y LORENTE FERNÁNDEZ, Virginia, Las fábricas y la ciudad (Málaga, 1834-1930). Arguval, Málaga, 2003.

6 (A)rchivo (H)istórico (M)unicipal de (M)álaga, leg. 1382, c. 128. 


\section{Q E artículos La Hacienda de Giró: un patrimonio emblemático...}

1. Hacienda de Giró. Archivo Temboury.

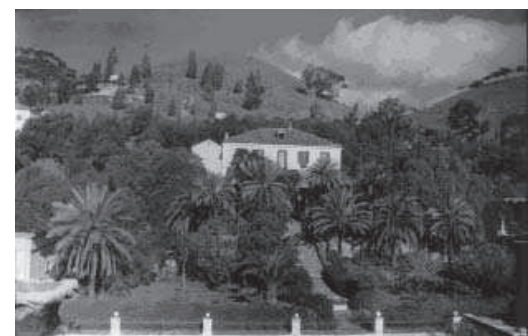

del viajero en Málaga de Benito Vilá, donde podemos leer:

“... el señor don Juan Giró, de nuestro comercio, acertó a dar a la obra emprendida el riguroso impulso y la recta y constante marcha que bien pronto produjeron los naturales resultados en beneficio de un progresivo crédito, siendo hoy este establecimiento uno de los mejores que, de su especie, cuenta nuestro país. La exquisita calidad de sus hierros (...) los hace muy estimados en la mayor parte de nuestras ciudades consumidoras y aun en las exposiciones universales celebradas últimamente en Londres y París se han concedido medallas y distintivos honoríficos para premiar las inmejorables condiciones de los hierros del Ángel"7.

En las proximidades de "El Ángel" se instaló la sociedad de fundición "La Malagueña" en un haza de tierra de la Hacienda de Muriel comprada a censo reservativo en 1844 y situada bajo el Camino de Vélez. Figura en el contrato como presidente de la Sociedad José Hernández Varela pero las letras de cambio están firmadas, y giradas desde Gibraltar, por Juan Giró a favor de María Sánchez Morales ${ }^{8}$.

\section{LA HACIENDA DE GIRO.}

De Juan Giró (1797-1872), personaje muy notable del momento -Comendador de la Real Orden de Carlos III- es poco lo que sabemos hasta ahora. Hijo de Juan Giró, natural de Mahón (Baleares) y de Ángela Morelo, de Gibraltar, era él también natural de Gibraltar. Llegó a Málaga desde Cádiz en fecha desconocida, pero nunca antes de 1824 , año en el que contrae matrimonio con $M^{a}$ Manuela de

7 VILÁ, Benito, Guía del viajero en Málaga, La llustración Española, Málaga, 1861.

8 A.H.P.M., leg. 4131, fol. 596. 


2: artículos Julia de la Torre Fazio

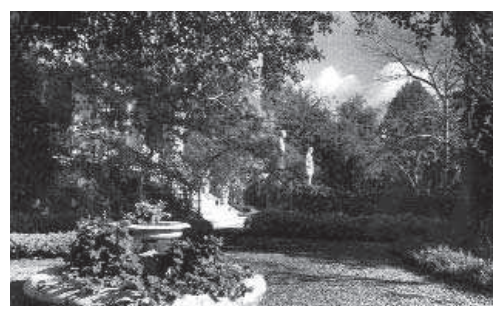

2. Jardines de la Hacienda de Giró. Archivo Temboury.

Aramburu Rodríguez, rica hacendada de origen limeño, en la iglesia de Nuestra Señora del Rosario de Cádiz 9 .

Su actividad empresarial estuvo en principio ligada a Manuel Agustín Heredia y otros destacados comerciantes malagueños en la sociedad anónima "Nuestra Señora de la Concepción"10. Tras desvincularse de este proyecto se une a otra sociedad, "El Ángel", de la que será director desde 1841 hasta su quiebra. Paralelamente, formó parte del Lloyd Malagueño, fundado en 1851 como "reunión o convenio de aseguradores particulares" en el que participaban todas las grandes firmas del comercio local ${ }^{11}$.

Giró, director de la Empresa Ferrería "El Ángel"12 al menos desde 1841, compra en 1853 una hacienda de campo con casa ventorrillo, nombrada de Muriel, a María Sánchez Morales, viuda de Joaquín Limendous. La finca se compone de viñas, arbolado y tierras manchones; consta de 14 fanegas y 7 celemines que lindan por el norte con tierras de Borrego, por levante con las de Antonio Vivas, por el sur con el Camino Real y por poniente con la Hacienda del Pelado y el Cementerio de los Ingleses ${ }^{13}$.

Esta finca rural se convertiría en una verdadera hacienda de recreo que conocemos por fotos de mitad del siglo XX. No se trataba solamente de una vivienda sino de un lugar representativo conforme a la categoría y el prestigio social de Giró. La casa disponía de grandes salones decorados con pinturas en sus techos y albergaba la rica colección de arte del matrimonio Giró-Aramburu. Delante de la casa, la terraza con su fantástico cierro de hierro, daba paso al gran jardín, único en la ciudad tanto por sus dimensiones como por su contenido. En él se unían esculturas,

9 A.H.M.M., leg. 4828,1867 , fols. $440-446$.

10 GARCÍA MONTORO, C.: La personalidad y obra de Manuel Agustín Heredia (1786-1846), tesis doctoral, Universidad Granada, Granada, 1976.

11 GARCÍA MONTORO, C.: "La Málaga del siglo XIX" en Historia de Málaga, Prensa Malagueña S.A., 1991.

12 A.H.M.M., leg. 1382, c. 128, 1841.

13 A.H.P.M., leg. 5001, 1853, fols. 663-699 
vegetación frondosa, fuentes de mármol, palmeras, parterres, nenúfares y ricas barandillas de hierro.

A la vista de estas fotos la pregunta inmediata es quién y cuándo mandó construir esta villa y jardín, que entronca, aunque mucho más modestamente, con La Concepción y San José. A pesar de la escasez de testimonios documentales parece fuera de toda duda que esa persona fue Juan Giró.

En su testamento observamos notables variaciones respecto al momento de compra. Junto a los viñedos y arbolado diverso se había construido un jardín con un pequeño manantial y una casa de recreo de $400 \mathrm{~m}^{14}$. La construcción del jardín, de considerables dimensiones, aca-

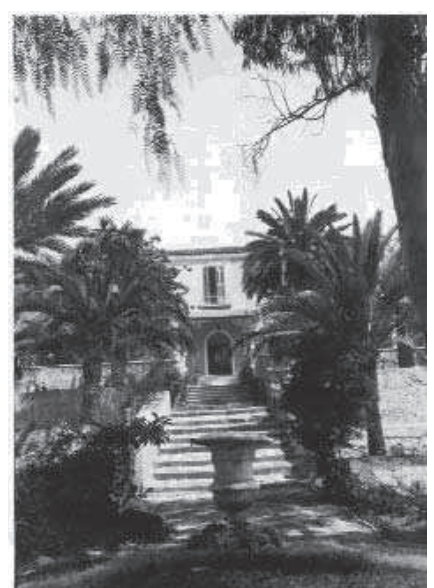

3. Hacienda de Giró. Archivo privado Kusche. rreó numerosos problemas a su propieta-

rio. Con fecha de 9 de noviembre de 1853 un informe del arquitecto municipal, José Trigueros, a la alcaldía hace suspender los trabajos que se estaban realizando en el jardín ${ }^{15}$. La Fuente de Reding, colindante a la propiedad, se había quedado seca y la causa era que las aguas que debían

llegar a ella estaban siendo almacenadas por la alberca, saltadores y fuentes de recreo de los jardines que se estaban construyendo en ese momento ${ }^{16}$.

También podemos documentar la construcción de una pared en la linde con el Camino de Vélez -actual Paseo de Sancha- en 1863. Según leemos en la autorización de la obra, la construcción de la pared tiene como objetivo "...quitar un callejón o apartadero de gente de mal vivir y que a ciertas horas de la noche impone a los que por allí transitan..."17.

A propósito de esta intervención resultan muy interesantes las palabras de María Pía Heredia y Grund que en su libro de memorias escribe lo siguiente: “...La

14 A.H.P.M., leg. 5226, 1881, fols. 3758-3764

15 Archivo Privado Kusche.

16 Para más información acerca de la historia de la Fuente de Reding vid. HURTADO SUÁREZ, Inmaculada: Op. Cit.

17 A.H.M.M., leg. 2234, c. 109, 1863. 


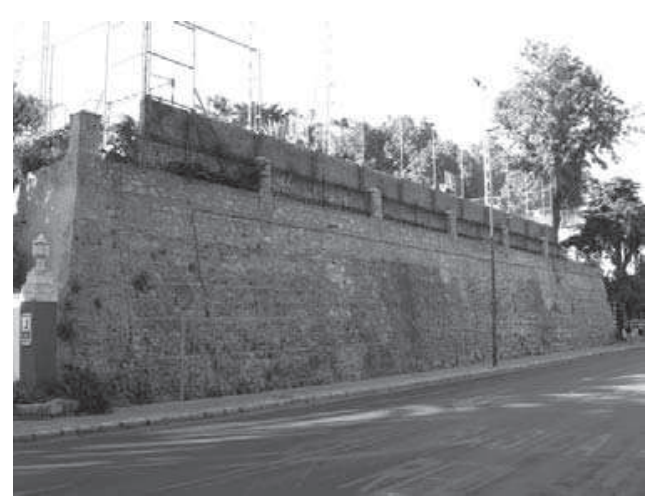

pared de la terraza a la playa les costó tanto que fue una locura. $Y$ de ahí el nombre que le quedó..." (La Folie Giró). ${ }^{18}$

Otro testimonio, esta vez gráfico, de las reformas de Giró lo tenemos en dos grabados, el que se conserva en el Archivo Díaz de Escovar y el publicado por la revista El mundo militar en 1858. En sendos grabados observamos una casa señorial con un pórtico a base de arcos y en el primero de ellos también un jardín aterrazado. Elementos que reconocemos, con cambios, en las fotografías del siglo XX y que nos permiten afirmar que fue Giró quien ideó y construyó la hacienda de recreo. Y debió de hacerlo al poco de comprar la finca, pues, el citado grabado muestra la quinta cedida por Giró a los convalecientes de la Guerra de África (1859-1860).

Además, y por si fuera necesaria una confirmación de la intervención de Giró, tenemos las barandillas y arcadas de hierro forjado repartidas por todo el terreno. ¿Quién, si no Giró, director de la ferrería "El Ángel", habría instalado con tanta prodigalidad hierro por toda la Hacienda?

Llegados a este punto conviene volver al personaje de Giró. Su condición de natural de Gibraltar le relaciona con el Consulado Británico, en virtud de lo cual le fue encomendada la subasta de los enseres salvados del naufragio del ISABELLA. EI ISABELLA era un bergantín inglés que transportaba esculturas y otros objetos de Génova a Calcuta por el estrecho de Gibraltar y que naufragó en la costa de Benalmádena en marzo de 1855. En un anuncio localizado en El Avisador

18 HEREDIA Y GRUND, María Pía, Memorias de una nieta de don Manuel Agustín Heredia, Madrid, 1955. 


\section{- E artículos La Hacienda de Giró: un patrimonio emblemático...}
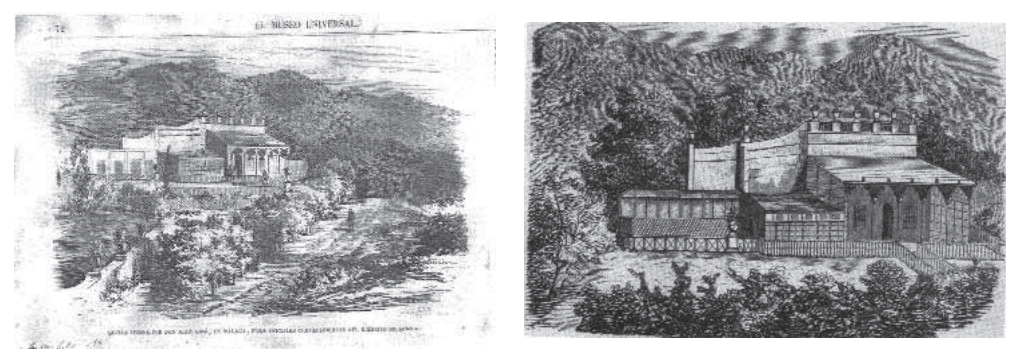

5. Hacienda de Giró. Archivo Díaz de Escovar. Fundación Unicaja.

6. Hacienda de Giró, "El Mundo Militar".

Malagueño los días 8 y 10 de abril de 1855 leemos: "VENTAS. Consulado británico. El miércoles 11 del corriente a las once de la mañana, se venderán en pública licitación en los almacenes de don Juan Giró, sitos en la Alameda de los Tristes, los despojos del casco y demás enseres del bergantín barca inglés nombrado ISABELLA, naufragado en las playas de Torrequebrada, distante una legua al Oeste de Torremolinos...". 19

Verosímilmente, y siguiendo la hipótesis lanzada por Rodríguez Oliva, Giró, el organizador de la subasta, se quedaría con algunas esculturas para colocarlas en su propio jardín. Teoría que se confirma cuando constatamos las similitudes entre las esculturas rescatadas recientemente (Artemis y Dionisos) y las que se encontraban en la Hacienda de Giró. La datación de estas esculturas dio lugar a alguna controversia, pues, en un principio se afirmó que eran romanas, tesis que pronto fue rebatida por Bianchi-Bandinelli: "La statua a me non sembra appartenere all'antichità greco-romana, ma piuttosto al secolo XVII o XVIII, come statua ornamentale da giardino". Rodríguez Oliva ha afinado algo más y apunta como fecha probable para su realización los años finales del siglo XVIII20. De lo que no cabe duda es de que procedian de talleres italianos -muy probablemente genoveses- y estaban concebidas como adorno para jardines.

En el jardín de Giró había varias esculturas aunque sólo de tres de ellas tene-

19 Recogido por RODRÍGUEZ OLIVA, P.: "Identificación del pecio de Torrequebrada (Benalmádena) y algunas noticias sobre la carga de obras de arte del navío inglés Westmorland" en Anuario de la Real Academia de Bellas Artes de San Telmo, Málaga, 2003.

20 Recogido por RODRÍGUEZ OLIVA, P.: La arqueología romana de Benalmádena, Excmo. Ayuntamiento de Benalmádena, Málaga, 1982. 


2: artículos Julia de la Torre Fazio
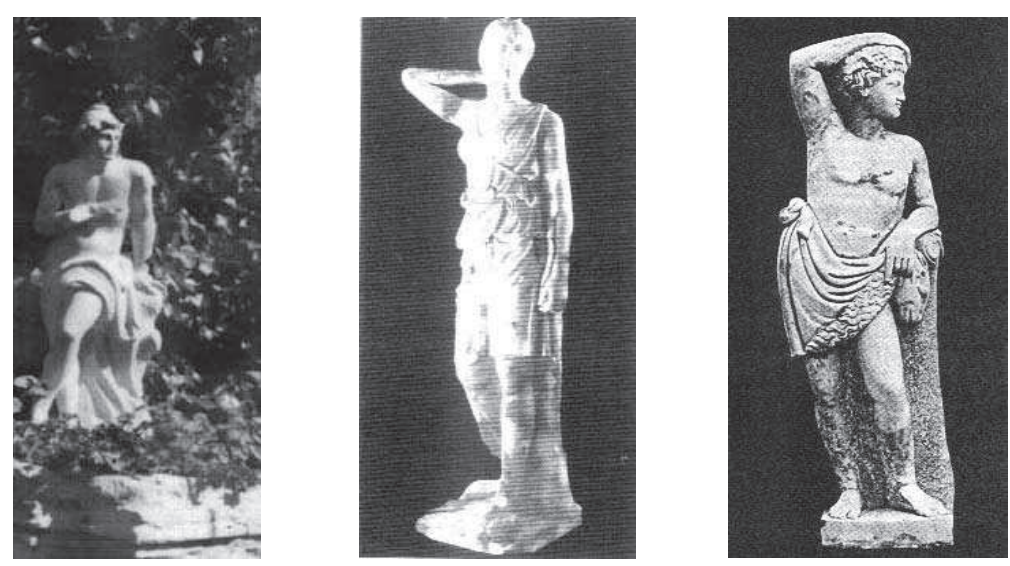

7. Escultura Hacienda de Giró. Archivo privado Kusche.

8. Artemis de Benalmádena. Museo Arqueológico Municipal de Benalmádena.

9. Dionisos de Torrequebrada. Museo Arqueológico de Málaga.

mos testimonio gráfico. Todas ellas eran dioses y figuras alusivas a la Naturaleza. Cuatro de ellas se encontraban flanqueando la escalera principal del jardín, en la parte superior de cada tramo; las demás se encontraban por diferentes rincones del jardín.

Su faceta como coleccionista de arte ha sido aún poco analizada. Sauret afirma que era dueño de una de las mejores colecciones privadas malagueñas 21 , basándose en dos catálogos diferentes. El primero - Catalogue des tableaux anciens de different écoles formant la colletion du Commander Juan Giró de Málaga22. fue realizado para la subasta de su colección (París, 1868). Podemos observar que ésta era de gran calidad e incluía obras de artistas como Murillo, Ribera, Giordano y Mengs, entre otros. En el segundo catálogo -Catálogo de la Exposición Retrospectiva celebrada por el Liceo de Málaga ${ }^{23}$-, posterior a la subasta, vemos cómo Giró aún con-

21 SAURET GUERRERO, T.: "Coleccionismo en Málaga en el siglo XIX. Del modelo tradicional a los nuevos intereses" en VII C.E.H.A. Patronos, promotores, mecenas y clientes, Universidad de Murcia, Murcia, 1988. 22 Catalogue des tableaux anciens de different écoles formant la colletion du Commander Juan Giró de Málaga dont la vente aura lieu, Hotel Drovot, Salle n 9, Le Samedi, 22 fevrier, 1868, Paris, 1868.

23 Catálogo de la Exposición Retrospectiva celebrada por el Liceo de Málaga en el mes de junio de 1874, Málaga, 1874 


\section{- E a troulos La Hacienda de Giró: un patrimonio emblemático...}
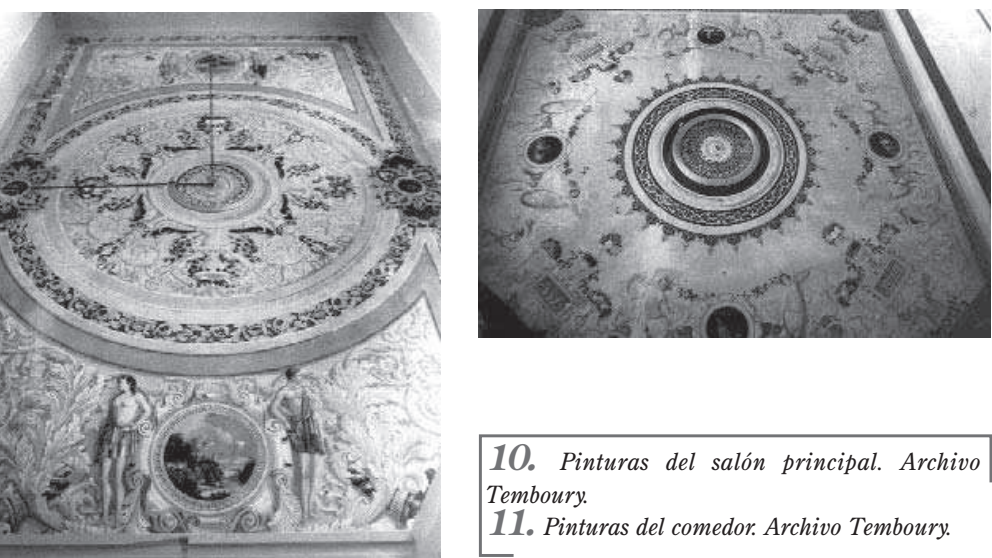

10. Pinturas del salón principal. Archivo Temboury.

11. Pinturas del comedor. Archivo Temboury.

servaba obras de interés: un retrato del Tiziano (escuela veneciana), La Sacra Familia (escuela española), varios grabados de Drevet, un grabado de Sigeot y Lacour, además de piezas de orfebrería pertenecientes a su mujer y procedentes de Perú.

Otra pequeña aportación para esclarecer su interés como coleccionista es el testamento de Felipe Pixon, en el que lega a John Giro "...la pintura de La Última Cena en la que ya tenía parte..."24, probablemente la misma que aparece en el catálogo de la subasta, obra de Matteo Rosselli (1603) ${ }^{25}$. También Vilá, en la ya mencionada Guía del viajero en Málaga, cita la colección de Giró, junto a las de Petersen, Clemens, Crooke y el marqués de Casa Loring, señalando que en ella existen pinturas notables 26 .

La reiterada constatación del interés de Giró por el arte nos inclinan a pensar que fue también él quien mandó hacer las pinturas, desafortunadamente perdidas, de las dos salas principales de la casa.

Diferentes estudios han tratado el tema de los interiores burgueses malagueños - Sauret 27 , Palomo 28 , García Gómez ${ }^{29}$, Fabre ${ }^{30}$ - , coincidiendo todos ellos en

24 A.H.P.M., leg. 4773 , fol. 626,1861

25 Catalogue, Op.Cit.

26 VILÁ, Benito, Op. Cit.

27 SAURET GUERRERO, T.: El siglo XIX en la pintura malagueña, Universidad de Málaga, Málaga, 1987. 28 PALOMO DÍAZ, F.: Historia social de los pintores del siglo XIX en Málaga, Málaga, 1985.

29 GARCíA GÓMEZ, F.: La vivienda malagueña del siglo XIX. Arquitectura y sociedad, Cajamar, Málaga, 2000 . 
presentarlos como un signo del posicionamiento social del propietario. En un artículo inédito, Sauret sostiene que estas pinturas constituyeron una práctica generalizada y que se caracterizan por su "escasa calidad, nulo interés iconográfico y fin meramente decorativo" 31 .

De las pinturas que nos ocupan es poco lo que se puede decir en cuanto a su cronología -segunda mitad del siglo XIX- y su autoría. El elenco de pintores decoradores de Málaga era muy amplio en aquellas fechas, siendo lo habitual recurrir a alguno de ellos. Manuel Montesinos había sido el maestro de esta plétora de pintores, creando un taller-escuela para decoradores y escenográfos en la Plaza de la Merced. Entre los alumnos destacó Antonio Matarredona, asiduo decorador de casas burguesas. Pero otros muchos nombres muy significativos de la pintura malagueña del siglo XIX se interesaron por esta práctica artística: Moreno Carbonero, Lengo, Jaraba, Maqueda, Martínez de la Vega y Denis Belgrano, entre otros 32 . Desde el punto de vista técnico, no eran frescos, sino pinturas al temple o lienzos encastrados en el cielo raso. Las pinturas de ambas salas, sin ser grandes obras, tenían un carácter festivo y alegre que proporcionaba una atmósfera muy agradable a las estancias. Presentaban una temática similar y un estilo neopompeyano común. En la sala principal, la pintura, en disposición rectangular, se dispone a base de un círculo central decorado con formas geométricas y vegetales y con un plafón circular para lámpara en su centro. En los dos laterales se repite el mismo esquema con sendos medallones pintados con paisajes y un atlante a cada lado, todo ello aderezado con rica ornamentación vegetal. Las figuras de los atlantes resultan especialmente interesantes para nuestro estudio, pues, si los observamos detenidamente guardan un parecido nada desdeñable con las esculturas del jardín. Posiblemente Giró mandó pintar unas figuras similares a las que él mismo poseía en ese mismo lugar.

En la sala de comedor, la pintura se organiza en torno al centro, con decoración geométrica circular y su correspondiente plafón. Se compone en este caso de candelieri, guirnaldas y amorcillos en un conjunto decorativo abigarrado con predominio de los elementos vegetales. En cada uno de los laterales del cuadrado descrito por la pintura se dispone un medallón con diferentes tipos de aves, en alusión, probablemente, al uso de comedor dado a esta sala.

Habiendo muerto Giró en junio de 1872 a causa de unas úlceras hipostáticas y también su único hijo y heredero, Juan Giró Aramburu, éste de viruelas, en diciem-

30 FABRE ESCAMILLA, E.: Enrique Jaraba Jiménez. Un pintor empresario en la Málaga de principios del siglo XIX, Universidad de Málaga, Málaga, 2002.

31 SAURET GUERRERO, T.: "Pintura e interiores burgueses en la Málaga del siglo XIX", artículo inédito.

32 Ibídem.

33 En los padrones municipales de 1883, 1886 y $1887^{34}$ figuran como habitantes Antonio Bermedo Luque y 


\section{Q E articulos La Hacienda de Giró: un patrimonio emblemático...}

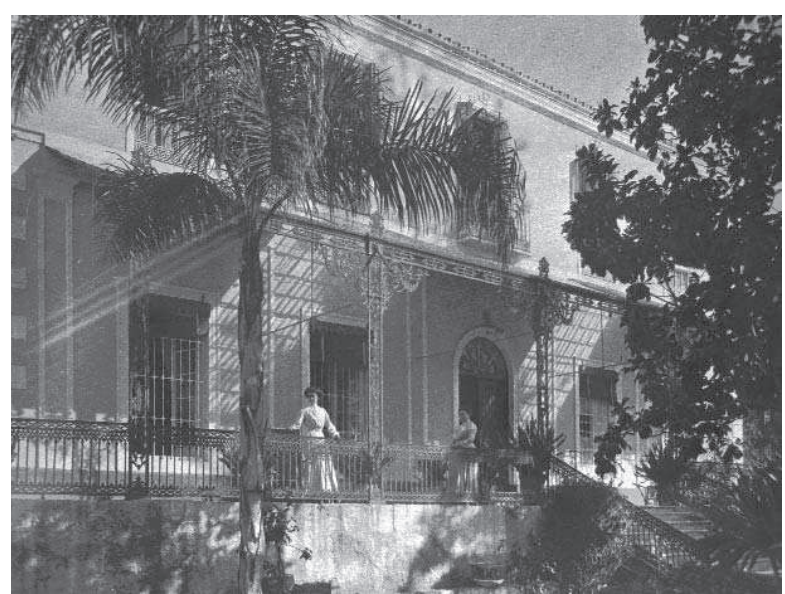

12. Terraza de la Pensión Cooper. Archivo privado Kusche.

bre de 1874, queda como heredera la viuda de Giró, Ma Manuela Aramburu. Ella abandonará la casa pero no la venderá hasta $1888^{33}$. El 14 de julio de ese año se firma el contrato de compra-venta con Tomás Heredia y Grund ${ }^{34}$.

En 1890 Heredia obtiene licencia para construir una casa frente a la de Teodoro Gross bajo dirección de Jerónimo Cuervo lindante con la carretera de Málaga a Almería35, en terreno de la Hacienda de Giró.

Respecto a la intervención de Heredia resulta especialmente interesante volver a las memorias de su hermana María Pía. En ellas leemos “...edificó en la carretera, antes de la fuente, tres casas cuyos planos hizo un arquitecto inglés, y son muy cómodas y bonitas. $Y$, después de la pared de contención, una o dos casas muy cómodas y bien repartidas; pero lo vendió todo ello pronto..." 36.

Parece que Heredia no vivió nunca en su nueva propiedad, sino que, volviendo a su hermana, la alquiló a una inglesa que puso una pensión ${ }^{37}$, Mrs. Cooper, de quien más adelante volveremos a tener noticia. Posiblemente Mrs. Cooper fue quien

su mujer, Josefa Gutiérrez Ruiz. A.H.M.M., Padrones municipales, vol. 643/2, 1883, vol. 688/2, 1886 y vol. 748/2, 1887.

35 Archivo Privado Kusche.

36 A.H.M.M., leg. 1315, c. 303, 1890.

37 HEREDIA Y GRUND, María Pía, Op. Cit. 


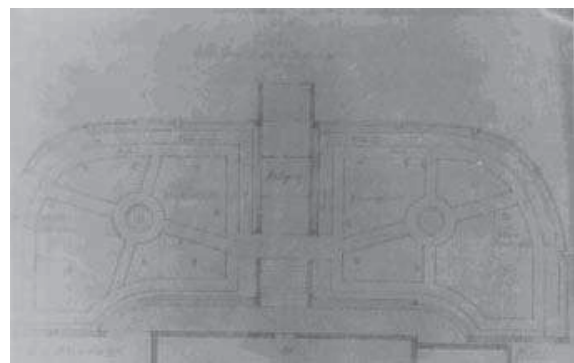

13. Proyecto del nuevo jardín. Archivo privado Kusche.

construyó un segundo piso a la casa, dedicado a habitaciones, para atender las necesidades de la pensión.

De aproximadamente estas fechas deben de ser dos fotos encontradas en el Archivo Kusche en las que se pueden ver a unos clientes de la pensión junto a la casa y paseando por los jardines.

En 1893 se documenta una nueva intervención en la Hacienda, aún propiedad de Heredia. Se trata de una autorización del propietario a Miguel Fernández para construir una caseta de madera provisional adosada al paredón del jardín de Giró38.

En fecha desconocida Heredia, o sus herederos, vendieron la Hacienda. Si creemos a María Pía, fue el propio Heredia el que realizó la venta, en cuyo caso ésta tendría lugar en 1893, pues, en agosto de este mismo año murió Heredia. No conocemos el nombre del comprador, si bien es probable que fuera Serafín Romen Fages, conde de Barbate, el siguiente propietario cuyo nombre conocemos. Romen Fages se dedicaba a la explotación de fábricas de conservas y salazones de pescados en Barbate e Isla Cristina. Tenía parte en diferentes empresas como "Romen y Cía.", "Compañía Almadrabera Española S.A." o "Viuda de Zamorano Romeu y Cía". Romen, natural de Madrid, no vivió ni explotó personalmente la Hacienda, sino que mantuvo el arrendamiento que Heredia había iniciado con Mrs. Cooper, una inglesa que regentaría la Pensión Cooper ${ }^{39}$ durante más de veinticinco años 40 .

En octubre de 1928 Ernesto Kusche ${ }^{41}$ compra para su suegro, Justus Strandes ${ }^{42}$, la antigua Hacienda de Giró al conde de Barbate que, domiciliado en

\section{8 idem.}

39 A.H.M.M. leg. 1282, c. 11, 1893.

40 BRAVO RUIZ, Natalia, "El Hotel 'Caleta-Palace': arquitectura de vacaciones y lujo para una 'Málaga Moderna' ", Boletín de Arte, $\mathrm{n}^{\circ}$ 18, Universidad de Málaga, 1997.

41 Archivo Privado Kusche.

42 Ernesto Kusche (Kassel 1878- Málaga 1965). Tras un aprendizaje comercial en Danzig se traslada a Málaga donde funda la sociedad Baquera, Kusche y Martin, consignataria de buques y agencia pionera en el turismo. Fue un gran coleccionista de arte español y se interesó mucho por la botánica. Archivo privado Kusche. 
Madrid, no tenía ni conocimiento ni interés en la finca malagueña. Strandes repartirá la Hacienda entre sus hijos y será, finalmente, Elisabeth Strandes de Kusche quien compre sus respectivas partes a sus hermanos para donar en 1945 la hacienda completa a sus hijas María y Eva Kusche. En un primer momento los nuevos propietarios continuarán el arrendamiento de Mrs. Cooper, decisión que parece ser no gustó a algún germanófilo a la vista de un anónimo recibido por Ernesto Kusche en el que bajo el título "Negocio y germanofilia" se le insta a crear una escuela alemana en su propiedad. Cuando Mrs. Cooper dejó el negocio se estableció un nuevo arrendamiento con Carl Heinz Faber, yerno de Kusche. Éste se firmó por el período 1934-1938, pero al estallar la Guerra Civil el edificio fue ocupado por las fuerzas nacionales y la Legión Cóndor como hospital de las Fuerzas Armadas.

Sólo pasados varios años después de la guerra española, en torno a 1945, se devolvió la finca a sus propietarios 43 .

\section{El Hotel Belaire.}

Recuperada la propiedad de la Hacienda de Giró se estableció un nuevo arrendamiento con unos holandeses. El por ellos llamado "Hotel Belaire" fracasó tras unos años, momento en el cual la propietaria, Elisabeth Strandes recoge el testigo del hotel, pero, de forma más modesta, opta por una pensión, más acorde a la situación española contemporánea.

"Necesita Vd. reposo, quiere Vd. pasar sus vacaciones agradablemente y con provecho, venga Vd. a Málaga donde encontrará en el Hotel Belaire (Hacienda de Giró) el sitio ideal para conseguir sus fines...

El Hotel que es una hermosa finca señorial de principio del siglo pasado, está situado en la famosa Caleta en medio de grandes jardines frente a la Bahía, apartado del ruido de la capital y sin embargo muy cerca del centro de ella. El Hotel reúne toda clase de confort, entre ellos el poder comer casi durante todo el año en las terrazas dada su orientación plenamente al Sur.

Asegúrese su habitación con tiempo pues el número de ellas está limitado (capacidad unas 45 personas).

Precio pensión completa (cat. Primera A). Ptas. 125-150 día, más el 15\% del servicio." 44

43 Justus Strandes (Hannover 1859-1930). Responsable en "Hansing y Cía" del comercio con África oriental, vivió durante diez años en Zanzíbar donde jugó un importante papel en la colonización alemana de África, destacando por la defena de las culturas existentes. A su vuetta fue nombrado senador de comarcio ca, destacando por la defensa de las culturas existentes. A su vuelta fue nombrado senador de comercio por alemán. Fue también un gran coleccionista de arte. Archivo privado Kusche.

44 Archivo Privado Kusche. 


\section{Q: artículos Julia de la Torre Fazio}
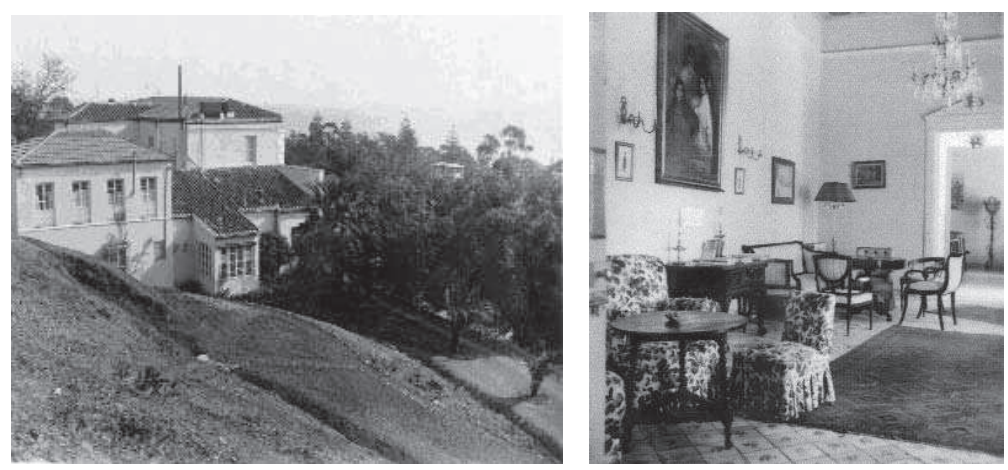

14. Ampliación del Hotel Belaire. Archivo privado Kusche.

15. Interior del salón principal. Archivo privado Kusche.

De esta manera se anunciaba el hotel en los folletos de los años treinta. Como un balneario, un lugar de descanso, para pasar largas temporadas lejos del frío del norte de Europa.

El diseño del jardín del Belaire fue modificado si bien respetando las líneas principales y la compartimentación en terrazas. Ya en un plano de noviembre de 1931 vemos la nueva composición. A ambos lados de la escalera se disponen sendas terrazas con una fuente en el centro y setos de flores alrededor, dejando pequeños caminos entre ellos para ser recorridos en los paseos de los huéspedes.

El rico arbolado y vegetación heredado de los primeros propietarios será objeto de especial atención por los nuevos dueños. Instalaron un invernadero y plantaron un jardín de cactus y junto con jardineros profesionales venidos de Alemania crearon un jardín exótico con especies únicas en el sur de España. Es decir, hicieron del jardín un lugar de interés botánico.

También la casa fue levemente modificada para adecuarse a las nuevas necesidades. Se llevó a cabo una ampliación hacia el monte del piso bajo con lo que se pudo disponer de un comedor apropiado para un hotel.

El interior de la casa contaba, además de con las pinturas ya mencionadas, con una decoración valiosa. El salón principal, pavimentado con unos preciosos azulejos, tenía muebles de estilo alemán e inglés y alguna pinturas de interés como el cuadro de Morcillo con dos gitanas.

Uno de los elementos más interesantes de esta etapa de la Hacienda de Giró 
Q artículos La Hacienda de Giró: un patrimonio emblemático...

es el descubrimiento en uno de los huertos inferiores de dos esculturas romanas, o de estilo romano: un águila imperial y una escultura thoracata. Fueron halladas por Ernesto Kusche al excavar para construir un huerto y él mismo, antes de vender la Hacienda, y velando por su conservación, las donó a un museo de Barcelona ${ }^{45}$. En 1959 Maria y Eva Kusche Strandes venden la Hacienda a "Acción Cultural, Sociedad Anónima" por quinientas mil pesetas. En aquellos momentos la propiedad comprendía 12.185 metros cuadrados dentro de los cuales existía una casa principal a dos plantas de 360 metros cuadrados, otras construcciones para garaje y portería, dos albercas, un aljibe y un pozo 46 . Una vez comprado el solar, "Acción Cultural", es decir, la Institución Teresiana, instaló en él su colegio. El edificio, de nueva planta, se construyó aprovechando los desniveles del monte en un espacio anteriormente ocupado por la explanada de entrada a la hacienda. Cuando éste estuvo finalizado, en 1963, el Hotel Belaire fue usado como residencia para teresianas y alumnas. Pero, a finales de los setenta, el Hotel fue derribado para construir en su lugar el Centro Almar, residencia de teresianas. De las pinturas nada queda, destruidas con toda probabilidad en el derribo de la casa; las esculturas sobrevivieron algunos años más escondidas entre los jardines, pero, finalmente desaparecieron.

Sólo se conserva una de las fuentes del jardín, situada en la actualidad delante del despacho de dirección del colegio 47 .

\section{A MODO DE CONCLUSIÓN.}

La desaparición de la Hacienda de Giró es un buen ejemplo de lo que nunca debería ocurrir48. Bien por desconocimiento, bien por desinterés o desidia, un conjunto histórico-artístico de gran interés en nuestra ciudad fue derribado y olvidado $-\mathrm{u}$ olvidado y derribado-. Nada podemos hacer ya por reconstruir la antigua Hacienda más que ponerla en valor y lamentar su desaparición, sin embargo sí que podemos reivindicar algunas construcciones hermanas como La Cónsula, El Retiro, Hacienda Jurado, La Concepción, San José, El Álamo, San Julián y alguna más.

\footnotetext{
45 Texto publicitario del Hotel Belaire. Archivo Privado Kusche.

46 En la actualidad estamos realizando investigaciones acerca del paradero de estas esculturas en contacto con diferentes especialistas.

47 Archivo Privado Kusche.

48 Ante la inexistencia de leyes de protección del patrimonio y preocupado por el conjunto, Ernesto Kusche realizó antes de la venta un acuerdo oral de conservación de la antigua Hacienda de Giró que, desgraciadamente, no fue respetado.
} 


Q: artículos Julia de la Torre Fazio

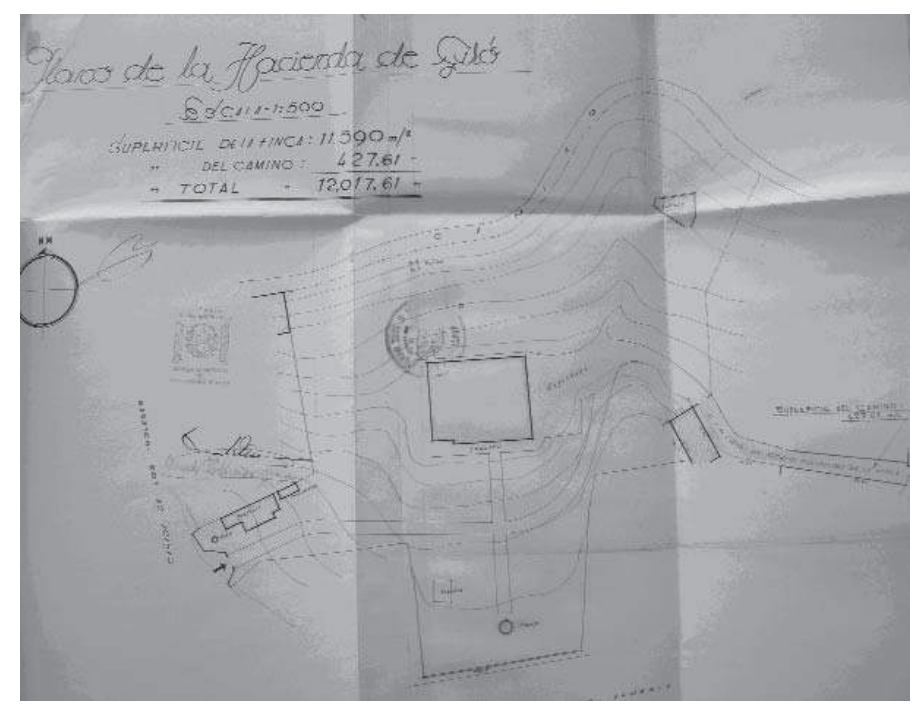

16. Plano del Hotel Belaire, 1959. Archivo privado Kusche. 